\title{
ABORDAGENS NOVAS NA ATENÇÃO DE ENFERMAGEM E A NECESSIDADE DE COMUNICAÇÃO ENTRE OS ENFERMEIROS DOS SERVIÇOS E DO ENSINO
}

\author{
Haydée Guanais Dourado*
}

\begin{abstract}
RBEn/06
DOURADO, H.C. - Abordagens novas na atençåo de enfermagem e a necessidade de comunicação entre os enfermeiros dos serviços e do ensino. Rev. Bras. Enf.; DF, 28 : 64-68 1976.
\end{abstract}

\section{INTRODUÇAOO}

Há necessidade contínua, por parte de todos aqueles que atuam no campo da enfermagem, que desenvolvam diálogo permanente a fim de contribuir para o desenvolvimento da profissão. A ação de reexaminar os assuntos em grupo tem interesse, uma vez que a profissão é nova na cultura e a linguagem de que se reveste 0 pensamento de pessoas variadas, se configura como um processo social.

E rico em mudanças e inovações o momento presente neste País. A enfermagem também participa de várias dessas mudanças. O presente trabalho deixará de abordar o contexto geral da cultura em que se passam tais inovações. Um documento sucinto que pode dar ao leitor tal contexto geral será o II Plano Nacional de Desenvolvimento, para o período 1975-1979. Outros aspectos da macro-enfermagem, que reconhecemos de grande importância, tais como a direção em que se movimenta o exer- cício atualmente, com o Conselho Federal de Enfermagem - e o ensino, de um modo geral, não são descritos, por serem amplos demais. Neste último caso, a reforma universitária e a reforma do ensino de $10^{\circ}$ e $2 .^{\circ}$ graus seguem as diretrizes da legislação federal, desde o advento da Lei 4.020 , de 1961 e 5.692, de 1971.

O presente trabalho tem por objetivo referir quatro mudanças que ocorrem na enfermagem - ensino e exercício - e as contrapor às relações de serviço entre os enfermeiros, para uma reflexão conjunta, sobre a necessidade de aperfeiçoar-se a administração de enfermagem, inclusive planejamento e pesquisa.

Tem-se como certo que as mudanças a.qui referidas beneficiam a enfermagem. Outras ainda deverão ocorrer. Para o cumprimento das metas constantes do Sistema Nacional de Saúde e do Plano Setorial de Educação, compatibilizados com o II Plano Nacional de Desenvolvimento, prosseguirá a evolução da enfermagem, não só para a consecução

- Professora Adjunta da Escola de Enfermagem Ana Neri, UFRJ. 
DOURADO, H.C. - Abordagens novas na atenção de enfermagem e a necessidare de comunıcaçäo entre os enfermeiros dos serviços e do ensino. Rev. Bras. Enf.; DF, 28 : 64-68 1976.

daqueles fins propostos, como também para os ajustamentos que se processam em toda a tela de vida, em decorrência das mudanças sociais contínuas.

\section{QUATRO MUDANÇAS EFETUADAS NA ENFERMAGEM}

Nos últimos anos tem havido, entre outras, as seguintes mudanças:

$\mathrm{Na}$ enfermagem obstétrica, ocorreram modificaçōes no que concerne à formação de enfermeiros e obstetrizes. A finalidade principal foi tornar mais sistêmica a educaçāo com tronco comum, e assim tirar proveito do fato social do País ter conseguido institucionalizar a enfermagem. Tiveram repercussão na legislação federal do ensino de enfermagem obstétrica e na criação dos Conselhos Federal e Regionais de Enfermagem.

Nos cursos de graduação de enfermeiros, além do descrito no item anterior, iniciaram-se mudanças, visando atender à reforma do ensino superior. Foram efetivas, em decorrência também de algumas variáveis entre as quais, o crescimento do mercado de trabalho e o aumento da população concluinte dos cursos do $2 .^{\circ}$ grau.

$\mathrm{Na}$ educaçāo continuada de enfermeiros, tiveram início os cursos de pósgraduação, cuja influência se fará sentir na qualidade da enfermagem do futuro. Também na educação, com grande vigor, se difundem em todo o País, os cursos de técnicos em enfermagem.

A quarta mudança é a melhora que deverá advir dos Conselhos Federal e Regionais de Enfermagem, no desempenho de suas competências legais, como órgãos de disciplina e ética das ocupaçōes de enfermagem. Em todos os serviços, o cumprimento dessas competências deverá resultar em certa institucionalização da assistência de enfermagem às populações.
Terminamos aqui a enumeração das mudanças que recentemente ocorrem com repercussāo na enfermagem. A seguir, serão referidos certos aspectos administrativos, de política educacional e outros, que dizem respeito à normalização da enfermagem organizada.

\section{AREA DE ENFERMAGEM E RECURSOS HUMANOS}

Do nosso ponto de vista, são quatro as áreas da enfermagem organizada: prática profissional, administração, docência e pesquisa. Aparecem também combinadas. Assessoramento e planejamento estarão compreendidos em todas, principalmente em administração.

E notório que os Governos passarão a ter metas de recursos humanos de enfermagem, uma vez que o assunto está recebendo atenção nestes últimos meses. Para as estratégias de sua implementação, as concepçōes que os enfermeiros têm e suas ações são de grande importância. Em última análise, o pessoal de enfermagem é que age ou deixa de agir, em seu campo.

também uma característica nova o trabalho conjunto do Ministério da Educação e Cultura com os Ministérios utilizadores dos recursos de enfermagem. Essa junçāo de esforços traz à classe uma esperança de um futuro melhor para a assistência à saúde.

Quanto à formaçāo de pessoal, há as providências que têm que ver com os candidatos que pela primeira vez ingressam para cursos no sistema de enfermagem. Aumento de docentes, de vagas, de candidatos, são exemplos deste aspecto.

Há também, providências para atender os que já estão do lado de dentro do sistema e devem progredir. Então a educação continuada e o aspecto sistêmico dos cursos são levados em consideração. O candidato com potencial de- 
DOURADO, H.C. - Abordagens novas na atençåo de enfermagem e a necessidade de comunicação entre os enfermeiros dos serviços e do ensino. Rev. Bras, En?.; DF, 28 : 64-68 1976.

verá poder progredir planejadamente de um nivel de ensino para outro. Os cursos devem oferecer a abertura. Este País tem respondido ao desafio de algumas questōes sociais que pōem em mira justiça e eqüidade. Estas últimas afirmaçōes dizem respeito a auxiliares de enfermagem, técnicos em enfermagem e enfermeiros.

ESTRUTURAS ORGANIZACIONAIS RELACIONADAS COM A ARTICULAÇAOO NA AREA DOCENTE - ASSISTENCIA

O atual projeto de lei que dispōe sobre o Sistema Nacional de Saúde atribul ao Ministério da Educação (precisamente a seus centros de ensino) a responsabilidade de formar profissionais universitários e de habilitar todo o pessoal de nível de $2 .^{\circ}$ grau para o setor saúde. Nos termos do Decreto-lei n.o 200, de 1967, cada Ministério tem sua responsabilldade própria, devendo-se gradualmente não só eliminar as duplicaçōes de esforço como cada um implementar seu plano setorial aprovado. Fm decorrência desse instrumento legal, os serviços utilizadores de enfermagem confiarão sempre aos centros de formação (educação) a responsabilidade de providenciar cursos (inclusive supletivos) realizados com a cooperação daqueles serviços.

Por outro lado, seguindo as deliberaçōes conjuntas dos Ministérios, aos hospitais de ensino é atribuida prestação de serviço de saúde atendendo, na medida do possivel, às necessidades comunitárias assim como aos hospitais da Previdência Social e de outras áreas de serviço é atribuído servirem de campo de ensino.

Desse modo, instituiçōes formadoras e utilizadoras poderão ter ao mesmo tempo atribuiçōes típicas de serviço e de ensino, que terão de ser realizadas em estruturas organizacionais de açōes várias, com inter-relação a ser definida, possivelmente em convênio.

A complexidade de um trabalho conjunto nas grandes empresas de saúde envolve, além dos aspectos técnico-científicos de cada profissão participante, os de administração dos vários profissionais, razão porque há necessidade de utilizar típicos processos da administração escolar e hospitalar. Em tal situação, utiliza-se comunicação do tipo de relaçōes secundárias, juntamente com a de relaçōes primárias*.

As consideraçōes sobre currículo conduzem à reflexão sobre o educando. Já nos dias de Florence Nightingale, sua excepcional visão de organizadora de serviços de enfermagem levou-a à seguinte estrutura: as alunas de enfermagem eram formadas em um tronco comum; com base em suas virtualidades para se desenvolverem como administradoras, determinadas alunas faziam curso de maior duração e conteúdo, incluindo administração. As soluçōes para os problemas na fase atual não pođem ser as mesmas do passado. Sem dúvida, a formação básica adequada e a adoção de um programa de educação continuada são partes de sua solução.

Examinando-se o Código de tíca da ABEn (contendo representaçöes coletivas), em sua forma aprovada em 1975, vêem-se as seguintes premissas para a enfermagem: é serviço prestado ao homem (portanto, com perspectiva integral), é uma das profissōes interdependentes da área da saúde; os enfermeiros têm um cerne comum de capacidade profissional. Adicionalmente faz-se a seguinte afirmativa: a sociedade necessita não só de enfermeiros especializados, mas também de um número maior de

- Pesquisa da autora. em andamento, aponta ser mais difícil o trabalho em grandes serviços de relacses secundérlas de que nos menores de relaçóes primárias. 
DOURADO, H.C. - Abordagens novas na atençăo de enfermagem e a necessidade de comunicaçăo entre os enfermeiros dos serviços e do ensino. Rev. Bras. Enf.; DF, 28 : 64-68 1976.

enfermeiros não especializados, porém, com o cerne de formação profissional, isto é, cientifica, técnica e com o ethos dessa profissão. $\mathbf{E}$ ainda, para o bem da atenção à saúde, convém que os enfermeiros desenvolvam maior iniciativa na equipe, não só na execução de serviços como no planejamento.

Finalmente, para se efetuarem as mudanças administrativas de que trata o presente trabalho, os grupos interprofissionais envolvidos, com as assessorias julgadas necessárias, têm sido os propulsores das alteraçōes desejadas, conforme se observa noutras situaçōes.

\section{PERSPECTIVA SISTAMICA E COMU- NICAÇAO NA ENFERMAGEM}

Segundo o relatório de 1966 denominado Senior Nursing Staff Structure (Salmon Report), do Departamento da Habitação e Saúde da Escócia, do Ministério da Saúde da Grã-Bretanha, as áreas de assistência de enfermagem $e$ as escolas de enfermagem continuam interligadas. Os Cargos em Comissão que existem em quatro níveis, são aqueles próprios de direção (ou coordenação) e de ensino de enfermagem.

Pode-se comentar o seguinte sobre 0 Salmon Report: as enfermeiras dos serviços e do ensino - ambos os grupos nos centros integrados previstos em suas estruturas organizacionais - dispōem de canais competentes para que os alunos de enfermagem se valham da pesquisa e dos resultados para o paciente, da atenção de enfermagem naquele determinado serviço, uma vez que suas professoras são responsáveis pelos pacientes. Dessa forma, o feed-back para o ensino estará continuamente assegurado.

Neste País, nos meios educionais está mais complexa a inserção, nos serviços hospitalares, das atividades de ensino de enfermagem. Por um lado, pode-se listar as quatro mudanças na enferma- gem, de início mencionadas neste trabalho, todas elas trazendo novas responsabilidades aos docentes das escolas. Pode acontecer que não tenha ocorrido o aumento do número de docentes em correspondência a essa demanda, ou que alguns desses docentes talvez não se tenham valido, em grau adequado, das oportunidades de educação continuada. Pesquisa especifica poderia constatar as relações de causa e efeito neste particular. Deve-se passar portanto, a cuidadosa reformulação das estruturas e normas de serviços de enfermagem, onde ficar evidente que é necessário.

O marco conceitual mais destacado quanto a atenção à saúde, em países desenvolvidos, é o preventivo e social. Empenham-se os educadores das proflssões de saúde na procura de integração desses componentes curriculares, - principalmente sua aplicação à prática profissiona:. Para atingir tal premissa, a abordagem sistêmica é o meio mais econômico e mais integralizador que está sendo divisado para esse fim referido.

de interesse continuar a perspectiva do processo de enfermagem, aqui visualizado em seu modo sistêmico e em vista de favorecer a comunicação intra e interprofissional. Em nosso País, tendo-se em vista que as condições de desenvolvimento não ensejam poder-se assumir em nível satisfatório a assistência de enfermagem plenamente e desde já, teremos que revigorar esse marco conceitual nas idéias e diretrizes que informam os planos, com conviç̧ão, sem o perder de vista, pondo-o em prática em todas as ocasiōes em que se possa fazer. Vale ressaltar que a própria criação da primeira escola de enfermagem, de nível do $3 .^{\circ}$ grau, teve a finalidade de completar as equipes para o fim de poderem trabalhar nos programas então inovadores, de assistência preventiva e social. 
DOURADO, H.C. - Abordagens novas na atenção de enfermagem e a necessidade de comunicação entre os enfermeiros dos serviços e do ensino. Rev. Bras. Enf.; DF, $28: 64-68$ 1976.

\section{CONSIDERAÇOESS FINAIS}

Empenham-se os educadores das profissōes de saúde na utilização dos processos escolhidos para que o produto final do aparelho formador seja o profissional voltado para a saúde das populaçōes. Dentre esses processos, está a integração dos componentes curriculares, principalmente sua aplicação à prática profissional. A abordagem sistêmica é um dos meios mais econômicos e integralizadores divisado para esse fim referido.

Dentro das abordagens novas, a área de administração na enfermagem é destacada para receber atenção especial, particularmente as estruturas organizacionais que propiciem a integração docência-assistência.

$A$ atenção à saúde nos países desen- volvidos tem o marco conceitual preventivo e social. No Brasil, os recursos financeiros que foram destacados para saneamento básico, bem como a preocupação com a distribuição de rendimentos, visto no II PND - 1975-1979, sugerem tomada de posição no mesmo sentido conceitual, embora o estágio de desenvolvimento do País não permita seja esse marco efetivamente posto em prática, em todas as áreas, principalmente nas rurais. Entramos, portanto, num tempo em que a criatividade e $o$ planejamento multiprofissional está surtindo efeito, ao procurar integrar saúde, educação (habilitação para o trabalho) e elevação geral do nível de vida das populaçōes (por saneamento, programas de habitação, entre outros). Nota-se que o enfoque preventivo, quanto à saúde, torna-se progressivamente aplicável.

\section{BIBLIOGRAFIA}

1. BRASIL. Presidência da República II Plano Nacional de Desenvolvimento, 1975-1979, Brasilia, 1975.

2. GRA-BRETANHA. Ministry of Health, Scottish Home and Health Department - Report of the Committee on Senior Nursing Staff Structure (The Salmon Report). London. Her Majesty's Stationery Office, 1966.

3. RERGIN, Dorothy - Seeing is Belleving. Toronto, University of Toronto Alumini Association, Relatório da Assembléia Anual de Delegados da Associaçāo Canadense de
Estudantes Universitários de Enfermagem, 23 p., 1975 (Mimeografado).

4. MCDHRMT, M.T. - Analisis Conceptual de la Enfermeria. Fm Educación Médica y Salud, OPAS/OMS, Washington, Vol. 7 (1) : 3-15, 1973.

5. PHLON, L.P. e Morales, R.I. - Consideraciones generales sobre la evoluación de escuelas de salud pública. Em Educación Médica y Salud, Washington, Organizaç5o Pan-americana de la Salud/OMS 8 (3): 244-252, 1974. 